\title{
Article \\ Ubiquinone Metabolism and Transcription HIF-1 Targets Pathway Are Toxicity Signature Pathways Present in Extracellular Vesicles of Paraquat-Exposed Human Brain Microvascular Endothelial Cells
}

\author{
Tatjana Vujić ${ }^{1,2}$, Domitille Schvartz ${ }^{1,2} \mathbb{D}$, Anton Iliuk ${ }^{3}$ and Jean-Charles Sanchez ${ }^{1,2, *}$ \\ 1 Department of Medicine, University of Geneva, 1206 Geneva, Switzerland; tatjana.vujic@unige.ch (T.V.); \\ domitille.schvartz@unige.ch (D.S.) \\ 2 Swiss Centre for Applied Human Toxicology, 4055 Basel, Switzerland \\ 3 Tymora Analytical Operations, West Lafayette, IN 47906, USA; anton.iliuk@tymora-analytical.com \\ * Correspondence: jean-charles.sanchez@unige.ch; Tel.: +41-22-379-54-86
}

Citation: Vujić, T.; Schvartz, D.; Iliuk, A.; Sanchez, J.-C. Ubiquinone Metabolism and Transcription HIF-1 Targets Pathway Are Toxicity Signature Pathways Present in Extracellular Vesicles of Paraquat-Exposed Human Brain Microvascular Endothelial Cells. Int. J. Mol. Sci. 2021, 22, 5065. https:// doi.org/10.3390/ijms22105065

Academic Editors: Annalisa Tassone and Leonora Balaj

Received: 20 April 2021

Accepted: 8 May 2021

Published: 11 May 2021

Publisher's Note: MDPI stays neutral with regard to jurisdictional claims in published maps and institutional affiliations.

Copyright: (c) 2021 by the authors. Licensee MDPI, Basel, Switzerland. This article is an open access article distributed under the terms and conditions of the Creative Commons Attribution (CC BY) license (https:// creativecommons.org/licenses/by/ $4.0 /)$.

\begin{abstract}
Over the last decade, the knowledge in extracellular vesicles (EVs) biogenesis and modulation has increasingly grown. As their content reflects the physiological state of their donor cells, these "intercellular messengers" progressively became a potential source of biomarker reflecting the host cell state. However, little is known about EVs released from the human brain microvascular endothelial cells (HBMECs). The current study aimed to isolate and characterize EVs from HBMECs and to analyze their EVs proteome modulation after paraquat (PQ) stimulation, a widely used herbicide known for its neurotoxic effect. Size distribution, concentration and presence of well-known EV markers were assessed. Identification and quantification of PQ-exposed EV proteins was conducted by data-independent acquisition mass spectrometry (DIA-MS). Signature pathways of PQ-treated EVs were analyzed by gene ontology terms and pathway enrichment. Results highlighted that EVs exposed to PQ have modulated pathways, namely the ubiquinone metabolism and the transcription HIF-1 targets. These pathways may be potential molecular signatures of the PQ-induced toxicity carried by EVs that are reflecting their cell of origin by transporting with them irreversible functional changes.
\end{abstract}

Keywords: extracellular vesicles; endothelial cells; paraquat; CNS; BBB; proteomics; DIA-MS; ubiquinone metabolism; oxidative stress; HIF-1; hypoxia

\section{Introduction}

Extracellular vesicles (EVs) are nanosized particles ( $<100 \mathrm{~nm}$ to $<1000 \mathrm{~nm}$ ) bounded by a lipid bilayer and exempt of nucleus that are naturally released by their cell of origin [1-4]. Due to the known heterogeneity of EVs, their size overlapping and the lack of specific markers to distinguish EV subsets, the minimal information for studies of extracellular vesicles 2018 (MISEV2018) recommended by the International Society for Extracellular Vesicles (ISEV) has not established as strict EV nomenclature. They are distinguished based on their size, namely small EVs $(<100$ or $<200 \mathrm{~nm})$ or/and as large EVs ( $>200 \mathrm{~nm}$ to $<1000 \mathrm{~nm}$ ) [2]. Since EVs carry nucleic acids, lipids, proteins and metabolites, they provide a valuable source of information that can be transferred into recipient cells and act as an "intercellular mediator" [3,4]. However, their composition may be strongly influenced by (patho-) physiological conditions and environmental stimuli of the cell of origin [4,5]. The EV content and delivery in the circulation of the neurovascular unit became an important field of research to understand their role in the physiology and pathologies of the central nervous system (CNS) [3,6,7].

Despite the existing studies published on EVs from a wide range of cell types, including endothelial cells, there is limited information available on EVs from human brain 
microvascular endothelial cells (HBMECs). Indeed, HBMECs are important, as they are one of the cell types composing the blood-brain barrier (BBB) $[8,9]$. In the human brain, HBMECs are playing a major role by joining tight junctions that constitute the anatomical foundation of the BBB $[8,10]$. HBMECs also assure the nutriment and macromolecule exchanges in the BBB [8], representing a crucial physiological interface between the blood and the CNS [11]. Nevertheless, in conditions where BBB is disturbed, for example by inflammation, a stroke or an exposure to a xenobiotic, the protecting role of HBMECs might be compromised [12]. BBB breakdown has already been described and linked to some neurodegenerative diseases such as Alzheimer's, Huntington's and Parkinson's diseases or multiple sclerosis $[9,13,14]$. Similarly, exposure to environmental toxicants might be a cause for the long-term development of neurodegenerative diseases $[15,16]$.

Paraquat (PQ), a commonly used herbicide, is transported by neutral amino acid transporters in the BBB and has already been demonstrated to have significant neurotoxic effect on the brain [17-21]. This xenobiotic also gained interest in the study of Parkinson's disease (PD), as its chemical structure is highly similar to the molecular model, 1-methyl4-phenyl-1,2,3,6-tetrahydropyridine (MPTP), used in Parkinson's disease research [22,23]. Despite the fact that several studies highlighted the oxidative stress as a major toxic effect of PQ in different brain cell types $[17,20,21,24]$, there is no available information on its effect on HBMEC-released EVs.

In the present study, EVs from primary human brain endothelial cells were characterized by mass spectrometry-based proteomics. The major finding of this study is that EVs exposed for $24 \mathrm{~h}$ to paraquat at $100 \mu \mathrm{M}$ displayed modulation of two biological pathways, which are highly significant: the ubiquinone metabolism and the transcription of HIF-1 targets. These two biological pathways highlight that EVs carried information from their parent cells, as they are two well-described pathways impacted by the PQ.

\section{Results}

\subsection{Characterization of Extracellular Vesicles from Human Brain Microvascular Endothelial Cells}

EVs from primary human brain microvascular endothelial cells were isolated using an EVtrap isolation method based on a chemical affinity capture approach, permitting to isolate small extracellular vesicles [25,26].

Three proteins were selected to confirm EV enrichment by western blots. PDCD6IP (Alix) and TSG101 are cytosolic proteins, whereas the calreticulin (CALR) is localized at the lumen of the endoplasmic reticulum, making it a suitable candidate as a negative enrichment control [27]. As shown in Figure 1A, detection of the PDCD6IP and TSG101 markers indicated a successful isolation of EVs [28]. Calreticulin was only present in whole cell lysate, which indicated low contamination from endoplasmic reticulum or apoptotic bodies in EVs [27].

To further characterize EVs, a proteomic analysis using mass spectrometry was conducted. Overall, a total of 1452 proteins were identified (Table S1). Typical EV markers, as PDCD6IP and TSG101, were confidently identified by mass spectrometry, confirming previous results.

A deep analysis of the identified proteins in EV samples highlighted that a majority of the proteins $(>70 \%)$ were annotated as EV proteins in Vesiclepedia, a reference database of extracellular vesicle composition [29]. Proteins from Vesiclepedia were filtered by selecting "homo sapiens" for species, "protein" for content types, "endothelial cell" for cell types and "mass spectrometry" for methods on FunRich 3.1.3 [29,30] (Figure 1B). In addition, mass spectrometry identified 85 proteins common to the Top $100 \mathrm{EV}$ markers annotated in the Vesiclepedia database [29]. 
A

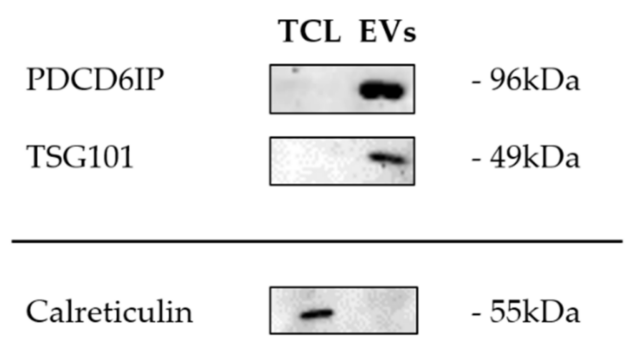

C

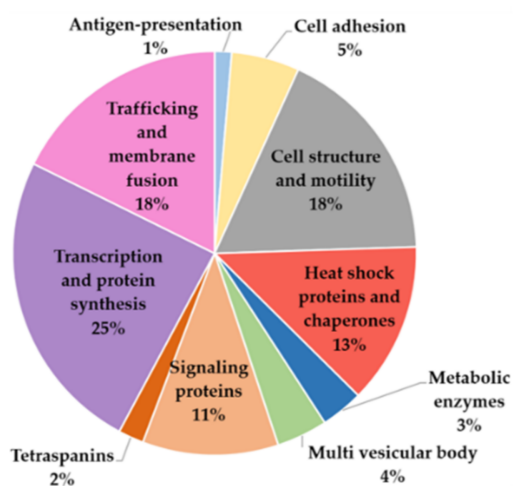

B

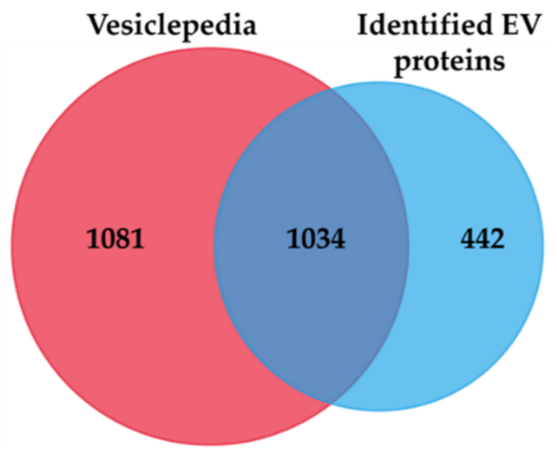

$\mathrm{D}$

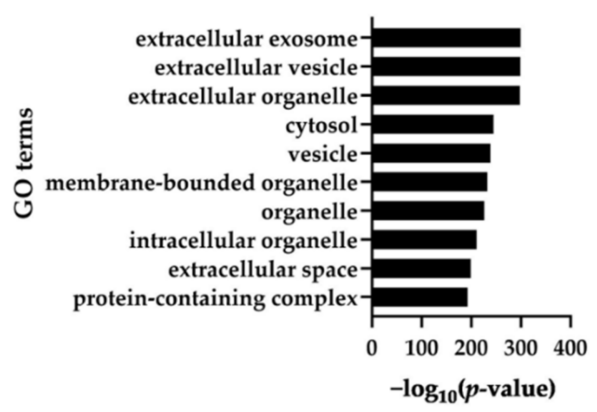

Figure 1. Characterization of extracellular vesicles from primary human brain microvascular endothelial cells (HBMECs). (A) Western blot analysis of common EV markers (PDCG6IP, TSG101) and cell organelle marker (calreticulin) in total cell lysate (TCL) and EVs. (B) Venn diagram of EV proteins extracted from Vesiclepedia (left) and identified proteins in HBMEC-released EVs (right). (C) Pie chart repartition of identified proteins in HBMEC-released EVs into EV functional categories. (D) Top ten cellular component enrichment of identified proteins in HBMEC-released EVs. X-axis corresponds to $-\log _{10}$ ( $p$-value), $Y$-axis corresponds to the GO terms. The $p$-value cut-off is set at 0.05 .

Moreover, by comparing to the work of Haqqani et al. [11], functional description of the identified proteins highlighted that "transcription and protein synthesis" $(25 \%)$, "cell structure and motility" $(18 \%)$, trafficking and membrane fusion proteins $(18 \%)$ and "heat shock proteins and chaperones" $(13 \%)$ are protein categories with a higher proportion in the pie chart (Figure 1C), representing key biological processes. Identified proteins are also part of other important functional categories in EVs, such as antigen-presentation proteins (HLAA and HLA-C), cell adhesion proteins (MFGE8, THBS1 and integrins), cell structure and motility proteins (ACTN, CFL1, TUB, MYH and MSN), heat shock proteins and chaperons proteins (HSP90, HSPA4, HSPA5, HSPA8 and HSPA9), multi vesicular body proteins (PDCD6IP, TSG101, CHMP3 and CHMP4B), signaling proteins (YWAH, ARHGDIA and RHOC), tetraspanin proteins (CD9, CD44 and CD59), trafficking and membrane fusion proteins (annexins and rab proteins) or transcription and protein synthesis (histones and ribosomal proteins) [11] (Table S2). These proteins are also described as EV markers in other EV proteomic studies, including those from BBB or endothelial cells [11,31-36].

To consolidate these results, a bioinformatics analysis was performed on the list of identified EV proteins. Enrichment of cellular component from Gene ontology (GO) ranked terms such as "extracellular exosome" (enrichment $p$-value of $4.05 \times 10^{-300}$ ), "extracellular vesicle" (enrichment $p$-value of $1.65 \times 10^{-299}$ ) and "extracellular organelle" (enrichment $p$ value of $5.09 \times 10^{-299}$ ) (Figure 1D) with highly significant $p$-values, confirming enrichment of EVs from primary brain endothelial cells.

\subsection{Modulation of Vesicular Protein Content after Paraquat (PQ) Exposure}

Before performing EV analyses from primary brain endothelial cells after paraquat exposure, paraquat-induced toxicity was evaluated for $24 \mathrm{~h}$ at different paraquat concen- 
trations on HBMECs. Cell proliferation was assessed by MTS Proliferation Assay and cell cytotoxicity by measuring LDH release. No effect was denoted on cytotoxicity or proliferation of HBMECs after PQ exposure at 1, 10 and $100 \mu \mathrm{M}$ (Figure S1). However, as a short exposure time $(24 \mathrm{~h})$ was chosen, it was decided to apply PQ concentration at $100 \mu \mathrm{M}$ to enhance the biological observation across the whole study.

To determine whether $24 \mathrm{~h}$ exposure to PQ at $100 \mu \mathrm{M}$ alters EV size distribution and concentration (particles $/ \mathrm{mL}$ ), a nanoparticle tracking analysis (NTA) was conducted. The control group presented a mean EV size of $126.70 \pm 10.10 \mathrm{~nm}$ and the PQ-treated group at $143.90 \pm 18.90 \mathrm{~nm}$ (Figure 2A), showing a slight significant difference between the two groups ( $p$-value $=0.0222$ ). EV concentration was also measured by NTA, resulting in $3.50 \times 10^{7} \pm 4.00 \times 10^{6}$ particles $/ \mathrm{mL}$ for the control group and $2.60 \times 10^{7} \pm 4.20 \times 10^{6}$ particles $/ \mathrm{mL}$ for the treated one (Figure $2 \mathrm{~B}$ ), indicating a significant difference in number of particles released between the two groups $(p$-value $=0.001)$. These results suggest that the size and concentration of EVs are impacted by PQ exposure. Additionally, NTA measurement demonstrated that EVs purified from primary endothelial cells (from control and treated group) were in the expected diameter range of small vesicles $(<100$ or $<200 \mathrm{~nm})$, validating the high selectivity of EV preparation [2].
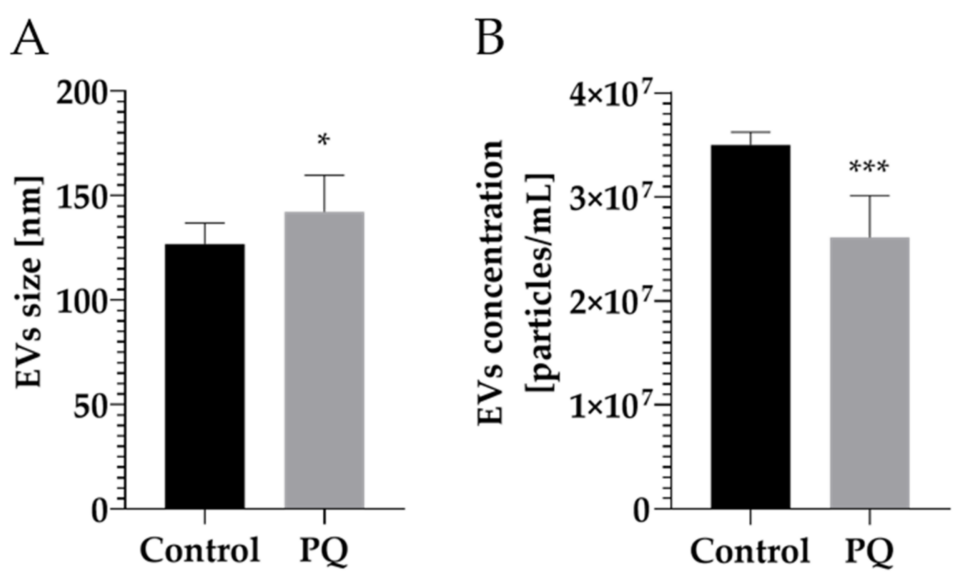

Figure 2. Nanoparticle tracking analysis (NTA) of isolated EVs from primary human brain microvascular endothelial cells in control and treated conditions. (A) Size distribution of HBMEC-released EVs in control and treated conditions. (B) Concentration of HBMEC-released EVs in control and treated conditions. All data were expressed as mean $\pm \mathrm{SD}$. ${ }^{*}$ corresponds to $p$-value $\leq 0.05$ and *** corresponds to $p$-value $\leq 0.0005$.

To evaluate proteome modifications in EVs under PQ exposure, a quantitative proteomic analysis was conducted by data-independent acquisition mass spectrometry (DIAMS). A total of 1452 proteins were quantified of which 107 were found to be differentially expressed (DE) in PQ-treated EVs $(|\mathrm{FC}|>1.2$; LFDR $\leq$ 0.05) (Figure S2 and Table S3). As illustrated in the volcano plot (Figure S2), among the most highly DE proteins of the 107 DE proteins, three (LOXL2, MMP2 and PHB2) are known to have a link with hypoxia response [37-39]. This observation permits to denote a previously described effect of the $\mathrm{PQ}$ induction of hypoxia-related pathways [40].

Gene Ontology (GO) enrichment analysis was performed, showing that most of the DE proteins were enriched with the highest significance in biological processes, such as GO terms related to oxidative processes (oxidative phosphorylation, oxidation-reduction process) and to mitochondria (ATP metabolic process, mitochondrion organization, electron transport chain) (Figure S3).

Pathway enrichment analysis was also performed using proteins significantly regulated upon PQ exposure. The results highlighted that paraquat modulates pathways of the ubiquinone metabolism (enrichment $p$-value of $2.56 \times 10^{-6}$ ) and the transcription of HIF-1 targets (enrichment $p$-value of $1.49 \times 10^{-4}$ ) pathways (Figure 3). Most of the 
other pathways uncovered were related to the hypoxia or the multifunctional cytokine, the TGF (Figure 3). These results reflect the well-described effect of the PQ as an oxidative stress inducer [18,41,42]. Indeed, enriched pathways found in EVs are corroborating the observation already noticed in HBMECs treated by PQ [43].

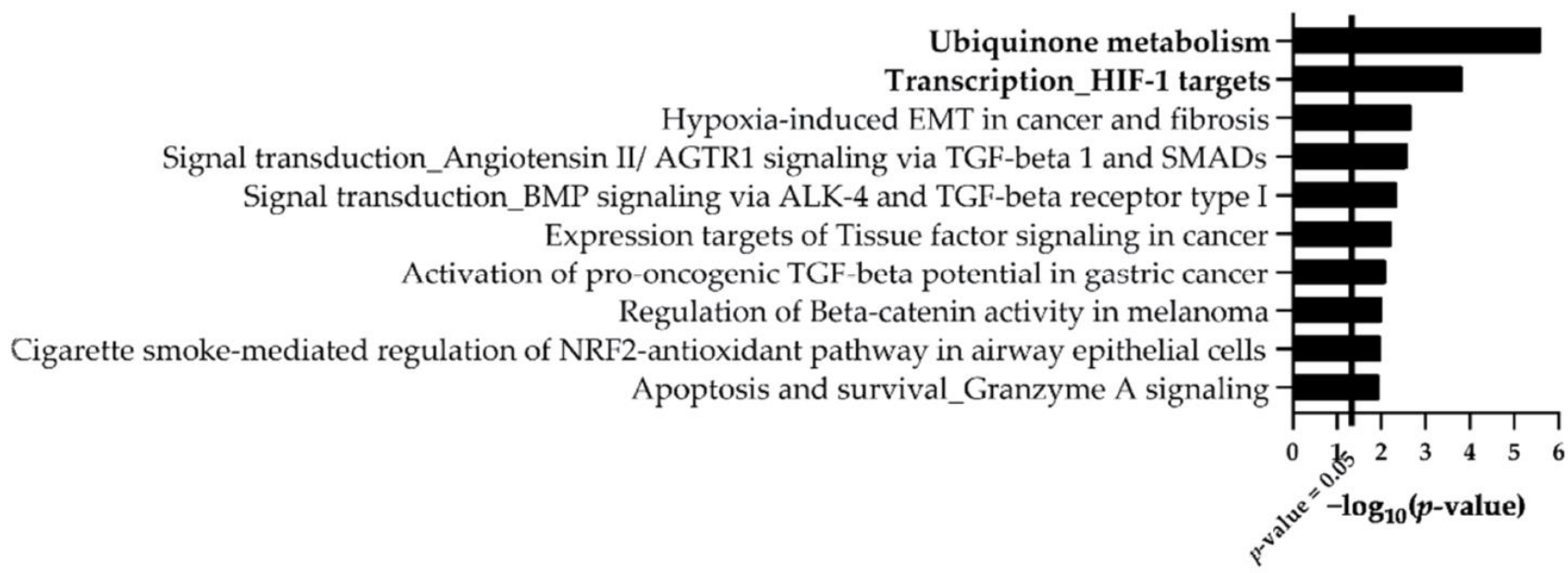

Figure 3. Top ten enriched biological pathways provided by MetaCore ${ }^{\mathrm{TM}}$ software for the lists of changing proteins $(|\mathrm{FC}|>1.2, p$-value $\leq 0.05, n=3)$ after PQ treatment on EVs from HMBECs. $X$-axis corresponds to $-\log _{10}(p$-value), $Y$-axis corresponds to the biological pathways and the vertical line represents the $p$-value cut-off of 0.05 .

\section{Discussion}

In the brain, accumulating studies have demonstrated that EVs are capable to cross the blood-brain barrier (BBB) [44,45], acting inside the CNS and at the periphery, which makes them valuable for biomarker research. However, unlike in other cellular types constituting the BBB (e.g., astrocytes, microglia or pericytes), EVs of human brain microvascular endothelial cells (HBMECs) were poorly characterized. This study aimed at examining the modulation of EV proteome profiles after paraquat (PQ) exposure using proteomics-based strategies.

EVs enriched by EVtrap met required EV physical characteristics according to the MISEV 2018 criteria [2]. Size distribution measured was lower than $200 \mathrm{~nm}$, underlying that EVtrap beads capture a small EV subset, as demonstrated in previous studies [25,26]. EVs were also shown by western blot to contain common well-characterized markers-PDCD6IP and TSG101 [28]. On the other hand, calreticulin was undetectable in EVs, indicating absence of cellular contamination. Moreover, proteins identified by mass spectrometry were shown to belong to different known categories of EV markers, highlighting that EVs captured by EVtrap were consistent with described EV composition. Cellular component enrichment revealed that most of the proteins were related to GO terms linked to "extracellular exosome", "extracellular vesicle" and "extracellular organelle" with highly significant $p$-values. These results were in accordance with previous proteomic findings [32,46,47], suggesting that EVs were properly isolated and enriched by EVtrap capture.

PQ concentration was chosen based on other studies using this xenobiotic [48-51] and was verified to be sufficient to withstand a physiological change without inducing a cytotoxic effect in the cell type of this study. As the exposure time to the toxin was relatively short ( $24 \mathrm{~h}$ ), the highest concentration was selected. Moreover, a study using other brain cells (astrocytes and neurons) and two toxins (paraquat and rotenone) has reported that both cell type were less sensitive to PQ compared to rotenone. To elicit significant effect by the toxin, they used PQ at $100 \mu \mathrm{M}$ after $24 \mathrm{~h}$ exposure, supporting PQ concentration chosen in our study [48]. To further evaluate EVs as "molecular signature" carriers from HBMECs after $24 \mathrm{~h}$ exposure of PQ at $100 \mu \mathrm{M}, \mathrm{NTA}$ analysis was performed. NTA measurement demonstrated a change in size distribution in PQ-treated EVs, which were bigger than the 
control. On the other hand, concentration (vesicles $/ \mathrm{mL}$ ) post-treatment was statistically lower compared to the control group. A study on microglia-derived extracellular vesicles stimulated with TNF- $\alpha$ reported similar trends by increasing mean size distribution and decreasing EV number [52], which suggests that an external stimulus would have an impact on EV size and concentration. However, other EV studies described the opposite, namely a decrease in size distribution and an increase in EV number after exposure to a stimulus [53]. Due to this controversial observation, it can be assumed that EV size and concentration may vary differently depending on the origin of the stimulus, its concentration, the biological material used or the isolation method chosen [52-55]. Nonetheless, one may speculate that a change in EV size or concentration would have an influence on their ability to fuse at the plasma membrane of a recipient cell as well as their uptake in the extracellular environment.

The quantitative mass spectrometry analysis of EVs from PQ-exposed HBMECs demonstrated that more than a hundred proteins were significantly modulated by the xenobiotic exposition. A large number of the differentially expressed proteins (DEP) are located in the mitochondria. Similarly, Gene Ontology (GO) terms enrichment highlighted GO terms such as "ATP metabolic processes", "mitochondrion organization" or "electron transport chain", which are closely related to the mitochondria. In addition, a quarter of DEP were linked to the oxidative phosphorylation directly associated to the complex I of mitochondria (NDUFA5, NDUFA9, NDUFA13, NDUFS2, NDUFS3, NDUFV1, ATP5H, ATP5O, ATP5J2, STOML2), as well as oxidation-reduction processes. One of the most described effect induced by $P Q$ is the generation of reactive oxygen species leading to altered biological processes related to cellular oxidation $[18,21,22]$. Moreover, PQ interaction with mitochondria remains the cornerstone of its toxicity mechanism, particularly in the brain $[18,24]$. These results are in line with our own study exploring the proteome by mass spectrometry of the entire PQ-treated cells [43]. Moreover, it can be presumed that cells stressed by paraquat exposure will result in damage to cellular membranes, permitting part of mitochondria to be released in the extracellular medium. A very recent study of D'Acunzo et al. identified a novel population of EVs of mitochondrial origin altered in Down syndrome [56]. Indeed, these EVs contain a specific subset of mitochondrial proteins [56]. These combined results confirm that altered EV protein content can mirror the molecular status of the parent cells, as demonstrated by other studies [56-62].

Finally, enrichment pathway analysis of EVs exposed to PQ highlighted "ubiquinone metabolism" and "transcription of HIF-1 targets" as pathways enriched with the highest significance. These results suggest that paraquat modulates mechanisms such as oxidative stress and hypoxia-related pathways in EVs. As described above, PQ is an oxidative stress inducer that inhibits respiratory chain complexes in the mitochondria (especially complex I, which is directly related to the ubiquinone metabolism) [24]. In addition, hypoxia-inducible factor- 1 (HIF-1) is a transcription factor sensitive to the oxygen species and regulates cellular response to changes in oxygen tension during normal development or pathologic processes [24]. HIF-1 has already been linked to PQ-induced toxicity in pulmonary fibrosis by increasing its expression [40,63]. Our proteomic profiles of PQtreated vesicles also demonstrated an action of PQ at the vesicular level by modulating the expression of proteins belonging to the ubiquinone metabolism as well as to the hypoxia downstream mechanisms. These observations are consolidating our assumption that EVs are reflecting PQ effects by carrying pathway signatures originating from parent cells. Likewise, a study on malignant brain tumor glioblastoma multiform concluded that the proteome and mRNA profile of EVs were a mirror of the oxygenation status found in cells and that the hypoxia-dependent intercellular signaling pathway may be a potential targeted driver during tumor development [60]. Nevertheless, the vesicular content, such as mRNAs and lipids, was not explored in this study. This raises interest to further research this topic adding complementary information about oxidative stress and hypoxia mechanisms as "signature pathways" modified by PQ in EVs [64,65]. Moreover, as a follow-up to this study, it would also be interesting to explore the interaction of EVs from primary brain endothelial cells with other components of the neurovascular unit (i.e., astrocytes, pericytes, neurons) 
in order to evaluate the vesicles-cells communication and to identify the molecules crossing the blood-brain barrier.

In conclusion, a qualitative proteomics study allowed us to confirm the proper isolation and enrichment of EVs from HBMECs. The quantitative portion of this study also provided the first insight into EV proteome profiles from HBMECs after a xenobiotic exposure such as PQ. Results suggested that proteins from EVs shared common modified biological pathways to their parent cell, most notably the ubiquinone metabolism and the transcription HIF-1 targets. Both pathways are mechanisms already reported in PQinduced toxicity in brain research, suggesting their potential use as "signature pathways" to demonstrate PQ effects on the BBB.

\section{Materials and Methods}

\subsection{Cell Culture}

Primary human brain microvascular endothelial cells (ACBRI 367, Cell Systems) were cultured onto a rat tail collagen type I-coated $(15 \mu \mathrm{g} / \mathrm{mL}$, Merck Millipore, Darmstadt, Germany) flask (T150) and maintained in complete endothelial cell growth medium-2 (EGM-2MV BulletKit, Lonza, Walkersville, Maryland) at $37^{\circ} \mathrm{C}$ in a $5 \% \mathrm{CO}_{2}$ incubator. At $80 \%$ confluence, cells were washed three times with phosphate-buffered saline (PBS, Life technologies, Bleiswijk, The Netherlands) solution containing calcium and magnesium. They were incubated at $37^{\circ} \mathrm{C}$ with $20 \mathrm{~mL}$ of complete endothelial cell growth medium2 containing $5 \%$ of heat-inactivated exosome-depleted fetal bovine serum (Gibco/Life technologies, Bleiswijk, The Netherlands) for $24 \mathrm{~h}$. Three T150 were treated with paraquat (Sigma-Aldrich, St. Louis, MO, USA) $(100 \mu \mathrm{M})$ for $24 \mathrm{~h}$. Afterwards, the medium was collected and used for the extracellular vesicle (EV) isolation. Cells were detached with Stempro Accutase (Gibco/Life technologies, Bleiswijk, The Netherlands) and washed three times with ice-cold Phosphate Buffered Saline (PBS, Gibco/Life technologies, Bleiswijk, The Netherlands), pelleted and dry-stored at $-80^{\circ} \mathrm{C}$.

\subsection{EV Isolation}

In each T150 flask, about 10 million of human brain endothelial cells were cultured. $20 \mathrm{~mL}$ of cell media were recovered. Cells and apoptotic bodies were removed using centrifugation $(2000 \mathrm{~g}, 20 \mathrm{~min})$. EVs were isolated with $1 \mathrm{~mL}$ of cell supernatant by using EVtrap magnetic beads provided by Tymora Analytical as a suspension in water.

The media loading buffer were added at 1:10 $v / v$ ratio of the cell supernatant. $24 \mu \mathrm{L}$ of EVtrap magnetic beads were added. The samples were incubated by end-over-end rotation for $1 \mathrm{~h}$, according to manufacturer's instructions. Following supernatant removal using a magnetic separator rack, the beads were washed with PBS and the EVs eluted by two 10-min incubations with $100 \mathrm{mM}$ of fresh elution solution. Both eluted EVs were pooled and either resuspended in $80 \mu \mathrm{L}$ of $0.2 \mu \mathrm{m}$-filtered water for nanoparticle tracking analysis (NTA) or dry-stored at $-80^{\circ} \mathrm{C}$.

\subsection{Nanoparticle Tracking Analysis (NTA)}

NTA was carried out using a Particle Metrix ZetaView®instrument (Particle Metrix $\mathrm{GmbH}$, Inning, Germany). EVs were diluted at $1 / 500$ with $0.2 \mu \mathrm{m}$-filtered PBS prior to analysis. To evaluate the total particle count and the overall size, the samples were measured in scatter mode using the $488 \mathrm{~nm}$ and standard instrument settings (sensitivity: 80, shutter: 100, min. brightness: 30; min. area: 10; max area: 1000). The samples were measured with ZetaView ${ }^{\circledR}$ software version 8.05.12 SP1 (Particle Metrix GmbH, Inning, Germany).

\subsection{Protein Extraction and Quantificatio}

Cell and EV pellets were resuspended in $80 \mu \mathrm{L}$ of $0.1 \%$ Rapigest (Waters, Milford, MA, USA) $100 \mathrm{mM} \mathrm{TEAB} \mathrm{(Sigma-Aldrich,} \mathrm{St.} \mathrm{Louis,} \mathrm{MO,} \mathrm{USA),} \mathrm{incubated} 10 \mathrm{~min}$ at $80^{\circ} \mathrm{C}$ and then sonicated (five cycles of $20 \mathrm{~s}$ with breaks on ice). Samples were then spun down 
$\left(14,000 \mathrm{~g}, 10 \mathrm{~min}, 4^{\circ} \mathrm{C}\right)$ and the supernatant was recovered. Protein content was measured using the Bradford assay (Bio-Rad, Hercules, CA, USA).

\subsection{Western Blot Analysis}

The equivalent of $10 \mu \mathrm{g}$ of proteins for cell samples and for EV samples were separated using electrophoresis on a $10 \% \mathrm{~T} / 2.6 \% \mathrm{C}$ polyacrylamide gel and were subsequently transferred onto a PVDF membrane. Membranes were stained with Amido black to highlight the proteins and washed with water to remove the excess. Immunoblot assays were performed using an anti-mouse antibody against PDCD6IP at a dilution of 1:500 (Biolegend, San Diego, CA, USA), anti-rabbit TSG101 at a dilution of 1:500 (Abcam, Cambridge, UK) and anti-rabbit calreticulin (negative marker) at a dilution of 1:100 (Abcam, Cambridge, UK).

\subsection{Sample Preparation for Mass Spectrometry-Based Proteomics}

For each sample, $5 \mu \mathrm{g}$ proteins was reduced using TCEP (final concentration $5 \mathrm{mM}$, $30 \mathrm{~min}, 37^{\circ} \mathrm{C}$ ) (Sigma-Aldrich, St. Louis, MO, USA), alkylated using iodoacetamide (final concentration $15 \mathrm{mM}, 60 \mathrm{~min}, \mathrm{RT}$, in dark condition) (Sigma-Aldrich, St. Louis, MO, USA) and digested by an overnight tryptic digestion ( $w / w$ ratio 1:50) (Promega, Madison, WI, USA). The RapiGest surfactant was cleaved by incubating samples with $0.5 \%$ trifluoacetic acid (Sigma-Aldrich, St. Louis, MO, USA) $\left(45 \mathrm{~min}, 37^{\circ} \mathrm{C}\right)$. Samples were then desalted on a $\mathrm{C} 18$ reverse phase column (Harvard Apparatus, Holliston, MA, USA), peptides were dried under vacuum and subsequently resuspended in $5 \%$ ACN $0.1 \%$ FA (peptides final concentration of $0.5 \mu \mathrm{g} / \mu \mathrm{L}$ and spiked with iRT peptide (Biognosys, Schlieren, Switzerland) $(1: 20))$.

\subsection{Data Independent Acquisition Mass Spectrometry (DIA-MS) and Data Analysis}

For each sample (cells and EVs), the equivalent of $2 \mu \mathrm{g}$ of peptides were analyzed using Liquid Chromatography-Electrospray ionization-MS/MS (LC-ESI-MS/MS) on an Orbitrap Fusion Lumos Tribrid mass spectrometer (Thermo Fischer Scientific) equipped with an EASY nLC1200 liquid chromatography system (Thermo Fisher Scientific). Peptides were trapped on a $2 \mathrm{~cm} \times 75 \mu \mathrm{m}$ i.d. PepMap C18 precolumn packed with $3 \mu \mathrm{m}$ particles and $100 \AA$ A pore size. Separation was performed using a $50 \mathrm{~cm} \times 75 \mu \mathrm{m}$ i.d. PepMap C18 column packed with $2 \mu \mathrm{m}$ and $100 \AA$ particles and heated at $50{ }^{\circ} \mathrm{C}$. Peptides were separated using a 160-min segmented gradient of $0.1 \%$ formic acid (solvent $\mathrm{A}$ ) and $80 \%$ acteonitril $0.1 \%$ formic acid (solvent B) at a flow rate of $250 \mathrm{nl} / \mathrm{min}$, following the published protocol [66]. Data-Independent Acquisition (DIA) was performed with MS1 full scan at a resolution of 60,000 (FWHM) followed by 30 DIA MS2 scan with variable windows. MS1 was performed in the Orbitrap with an AGC target of $1 \times 10^{6}$, a maximum injection time of $50 \mathrm{~ms}$ and a scan range from 400 to $1250 \mathrm{~m} / \mathrm{z}$. DIA MS2 was performed in the Orbitrap using higher-energy collisional dissociation (HCD) at 30\%. Isolation windows (30) were variables with an AGC target of $2 \times 10^{6}$ and a maximum injection time of $54 \mathrm{~ms}$. The raw DIA MS data were matched against the spectral library following the published protocol [66].

For the analysis of cells and EVs, protein abundances were exported from Spectronaut ${ }^{\mathrm{TM}}$, and selected proteins were tested for significance using Student's two-tailed $\mathrm{t}$-test. Proteins and peptide intensities were exported and analyzed using mapDIA. No further normalization was applied. The following parameters were used: min peptides $=2$, max peptides $=10$, min correl $=-1 . \min \mathrm{DE}=0.01, \max \mathrm{DE}=0.99$ and experimental design $=$ replicate design. Proteins were considered to have significantly changed in abundance with a LFDR $<0.05$ and an absolute fold change $(|F C|)>1.2$. Data are available via ProteomeXchange with identifier PXD024691. 


\subsection{Enrichment Pathway Analysis}

The list of differentially expressed proteins was then analyzed with MetaCore ${ }^{\mathrm{TM}}$ version 21.1 (Clarivate Analytics, Philadelphia, PA, USA) to highlight significantly represented biological pathways. Top 10 biological pathways were selected.

\subsection{MST Proliferation and LDH Cytotoxicity Assay}

HBMEC were seeded in a 96-well plate (10,000 cells per well) and treated for $24 \mathrm{~h}$ with PQ at different concentrations $(0.1,1,10,100,500$ and $1000 \mu \mathrm{M})$. Cell proliferation was determined using the MTS assay (CellTiter $96^{\circledR}$ AQueous One Solution Cell Proliferation Assay, Promega, Madison, WI, USA), whereas cytotoxicity was assessed by measuring lactate dehydrogenase (LDH) released using a Pierce ${ }^{\mathrm{TM}} \mathrm{LDH}$ cytotoxicity kit (Thermo Scientific, Rockford, IL, USA). Both the MTS and LDH assays were performed according to the manufacturer's recommendations.

\subsection{Statistical Analysis}

Data are reported as mean \pm standard deviation (SD). $p<0.05$ was considered as statistically significant. Significance is denoted as $*<0.05, * * p<0.01$, ${ }^{* * *} p<0.001$, $* * * * *<0.0001$. The data were analyzed using multiple t-test comparisons or one-way analysis of variance (ANOVA).

Supplementary Materials: The following are available online at https:/ /www.mdpi.com/article/10 .3390/ijms22105065/s1.

Author Contributions: Conceptualization, T.V., D.S. and J.-C.S.; methodology, T.V.; validation, T.V., D.S. and J.-C.S.; formal analysis, T.V.; investigation, T.V.; resources, A.I. and J.-C.S.; data curation, T.V. and D.S.; writing—original draft preparation, T.V.; writing—review and editing, T.V., D.S., J.-C.S. and A.I.; visualization, T.V. and D.S.; supervision, J.-C.S.; project administration, J.-C.S.; funding acquisition, J.-C.S. All authors have read and agreed to the published version of the manuscript.

Funding: This research was funded by the Swiss Centre for Applied Human Toxicology (SCAHT).

Institutional Review Board Statement: Not applicable.

Informed Consent Statement: Not applicable.

Data Availability Statement: Not applicable.

Acknowledgments: We are grateful to the Swiss Centre for Applied Human Toxicology for funding this study. We also want to thank Alexandre Hainard, Carla Pasquarello and Patrizia Arboit from the proteomic core facility at Geneva University for their kind help and advice for the proteomic analyses by mass spectrometry.

Conflicts of Interest: The authors declare no conflict of interest.

\section{References}

1. Lotvall, J.; Hill, A.F.; Hochberg, F.; Buzas, E.I.; Di Vizio, D.; Gardiner, C.; Gho, Y.S.; Kurochkin, I.V.; Mathivanan, S.; Quesenberry, P.; et al. Minimal experimental requirements for definition of extracellular vesicles and their functions: A position statement from the International Society for Extracellular Vesicles. J. Extracell. Vesicles 2014, 3, 26913. [CrossRef] [PubMed]

2. Théry, C.; Witwer, K.W.; Aikawa, E.; Alcaraz, M.J.; Anderson, J.D.; Andriantsitohaina, R.; Antoniou, A.; Arab, T.; Archer, F.; Atkin-Smith, G.K.; et al. Minimal information for studies of extracellular vesicles 2018 (MISEV2018): A position statement of the International Society for Extracellular Vesicles and update of the MISEV2014 guidelines. J. Extracell. Vesicles 2018, 7, 1535750. [CrossRef] [PubMed]

3. Yanez-Mo, M.; Siljander, P.R.; Andreu, Z.; Zavec, A.B.; Borras, F.E.; Buzas, E.I.; Buzas, K.; Casal, E.; Cappello, F.; Carvalho, J.; et al. Biological properties of extracellular vesicles and their physiological functions. J. Extracell. Vesicles 2015, 4, 27066. [CrossRef] [PubMed]

4. Van Niel, G.; D'Angelo, G.; Raposo, G. Shedding light on the cell biology of extracellular vesicles. Nat. Rev. Mol. Cell Biol. 2018, 19, 213-228. [CrossRef]

5. De Jong, O.G.; Verhaar, M.C.; Chen, Y.; Vader, P.; Gremmels, H.; Posthuma, G.; Schiffelers, R.M.; Gucek, M.; van Balkom, B.W. Cellular stress conditions are reflected in the protein and RNA content of endothelial cell-derived exosomes. J. Extracell. Vesicles 2012, 1. [CrossRef] 
6. Saeedi, S.; Israel, S.; Nagy, C.; Turecki, G. The emerging role of exosomes in mental disorders. Transl. Psychiatry 2019,9 , 122. [CrossRef]

7. Caruso Bavisotto, C.; Scalia, F.; Marino Gammazza, A.; Carlisi, D.; Bucchieri, F.; Conway de Macario, E.; Macario, A.J.L.; Cappello, F.; Campanella, C. Extracellular Vesicle-Mediated Cell(-)Cell Communication in the Nervous System: Focus on Neurological Diseases. Int. J. Mol. Sci. 2019, 20, 434. [CrossRef]

8. Serlin, Y.; Shelef, I.; Knyazer, B.; Friedman, A. Anatomy and physiology of the blood-brain barrier. Semin. Cell Dev. Biol. 2015, 38, 2-6. [CrossRef]

9. Varatharaj, A.; Galea, I. The blood-brain barrier in systemic inflammation. Brain Behav. Immunity 2017, 60, 1-12. [CrossRef]

10. Poller, B.; Gutmann, H.; Krahenbuhl, S.; Weksler, B.; Romero, I.; Couraud, P.O.; Tuffin, G.; Drewe, J.; Huwyler, J. The human brain endothelial cell line hCMEC/D3 as a human blood-brain barrier model for drug transport studies. J. Neurochem. 2008, 107, 1358-1368. [CrossRef]

11. Haqqani, A.S.; Delaney, C.E.; Tremblay, T.L.; Sodja, C.; Sandhu, J.K.; Stanimirovic, D.B. Method for isolation and molecular characterization of extracellular microvesicles released from brain endothelial cells. Fluids Barriers CNS 2013, 10, 4. [CrossRef]

12. Sweeney, M.D.; Zhao, Z.; Montagne, A.; Nelson, A.R.; Zlokovic, B.V. Blood-Brain Barrier: From Physiology to Disease and Back. Physiol. Rev. 2019, 99, 21-78. [CrossRef]

13. Barar, J.; Rafi, M.A.; Pourseif, M.M.; Omidi, Y. Blood-brain barrier transport machineries and targeted therapy of brain diseases. Biolmpacts BI 2016, 6, 225-248. [CrossRef]

14. Sweeney, M.D.; Sagare, A.P.; Zlokovic, B.V. Blood-brain barrier breakdown in Alzheimer disease and other neurodegenerative disorders. Nat. Rev. Neurol. 2018, 14, 133. [CrossRef]

15. Yegambaram, M.; Manivannan, B.; Beach, T.G.; Halden, R.U. Role of environmental contaminants in the etiology of Alzheimer's disease: A review. Curr. Alzheimer Res. 2015, 12, 116-146. [CrossRef]

16. Chen, H.; Ritz, B. The Search for Environmental Causes of Parkinson's Disease: Moving Forward. J. Parkinsons Dis. 2018, 8, S9-S17. [CrossRef]

17. Drechsel, D.A.; Patel, M. Chapter 21 Paraquat-induced production of reactive oxygen species in brain mitochondria. Methods Enzymol. 2009, 456, 381-393. [CrossRef]

18. Tawara, T.; Fukushima, T.; Hojo, N.; Isobe, A.; Shiwaku, K.; Setogawa, T.; Yamane, Y. Effects of paraquat on mitochondrial electron transport system and catecholamine contents in rat brain. Arch. Toxicol. 1996, 70, 585-589. [CrossRef]

19. Fukushima, T.; Yamada, K.; Hojo, N.; Isobe, A.; Shiwaku, K.; Yamane, Y. Mechanism of cytotoxicity of paraquat: III. The effects of acute paraquat exposure on the electron transport system in rat mitochondria. Exp. Toxicol. Pathol. 1994, 46, 437-441. [CrossRef]

20. Zhang, X.-f.; Thompson, M.; Xu, Y.-h. Multifactorial theory applied to the neurotoxicity of paraquat and paraquat-induced mechanisms of developing Parkinson's disease. Lab. Investig. 2016, 96, 496. [CrossRef]

21. Sandström, J.; Broyer, A.; Zoia, D.; Schilt, C.; Greggio, C.; Fournier, M.; Do, K.Q.; Monnet-Tschudi, F. Potential mechanisms of development-dependent adverse effects of the herbicide paraquat in 3D rat brain cell cultures. Neurotoxicology 2017, 60, 116-124. [CrossRef]

22. Dinis-Oliveira, R.J.; Remião, F.; Carmo, H.; Duarte, J.A.; Navarro, A.S.; Bastos, M.L.; Carvalho, F. Paraquat exposure as an etiological factor of Parkinson's disease. Neurotoxicology 2006, 27, 1110-1122. [CrossRef]

23. Brown, T.P.; Rumsby, P.C.; Capleton, A.C.; Rushton, L.; Levy, L.S. Pesticides and Parkinson's disease-is there a link? Environ. Health Perspect. 2006, 114, 156-164. [CrossRef]

24. Castello, P.R.; Drechsel, D.A.; Patel, M. Mitochondria are a major source of paraquat-induced reactive oxygen species production in the brain. J. Biol. Chem. 2007, 282, 14186-14193. [CrossRef]

25. Wu, X.; Li, L.; Iliuk, A.; Tao, W.A. Highly Efficient Phosphoproteome Capture and Analysis from Urinary Extracellular Vesicles. J. Proteome Res. 2018, 17, 3308-3316. [CrossRef]

26. Iliuk, A.; Wu, X.; Li, L.; Sun, J.; Hadisurya, M.; Boris, R.S.; Tao, W.A. Plasma-Derived Extracellular Vesicle Phosphoproteomics through Chemical Affinity Purification. J. Proteome Res. 2020, 19, 2563-2574. [CrossRef]

27. Men, Y.; Yelick, J.; Jin, S.; Tian, Y.; Chiang, M.S.R.; Higashimori, H.; Brown, E.; Jarvis, R.; Yang, Y. Exosome reporter mice reveal the involvement of exosomes in mediating neuron to astroglia communication in the CNS. Nat. Commun. 2019, 10, 4136. [CrossRef]

28. Yoshioka, Y.; Konishi, Y.; Kosaka, N.; Katsuda, T.; Kato, T.; Ochiya, T. Comparative marker analysis of extracellular vesicles in different human cancer types. J. Extracell. Vesicles 2013, 2. [CrossRef]

29. Pathan, M.; Fonseka, P.; Chitti, S.V.; Kang, T.; Sanwlani, R.; Van Deun, J.; Hendrix, A.; Mathivanan, S. Vesiclepedia 2019: A compendium of RNA, proteins, lipids and metabolites in extracellular vesicles. Nucleic Acids Res. 2019, 47, D516-D519. [CrossRef]

30. Fonseka, P.; Pathan, M.; Chitti, S.V.; Kang, T.; Mathivanan, S. FunRich enables enrichment analysis of OMICs datasets. J. Mol. Biol. 2020, 166747. [CrossRef]

31. Hromada, C.; Mühleder, S.; Grillari, J.; Redl, H.; Holnthoner, W. Endothelial Extracellular Vesicles-Promises and Challenges. Front. Physiol. 2017, 8, 275. [CrossRef] [PubMed]

32. Dozio, V.; Sanchez, J.C. Characterisation of extracellular vesicle-subsets derived from brain endothelial cells and analysis of their protein cargo modulation after TNF exposure. J. Extracell. Vesicles 2017, 6, 1302705. [CrossRef] [PubMed]

33. András, I.E.; Toborek, M. Extracellular vesicles of the blood-brain barrier. Tissue Barriers 2016, 4, e1131804. [CrossRef] [PubMed] 
34. Simeone, P.; Bologna, G.; Lanuti, P.; Pierdomenico, L.; Guagnano, M.T.; Pieragostino, D.; Del Boccio, P.; Vergara, D.; Marchisio, M.; Miscia, S.; et al. Extracellular Vesicles as Signaling Mediators and Disease Biomarkers across Biological Barriers. Int. J. Mol. Sci. 2020, 21, 2514. [CrossRef]

35. Mir, B.; Goettsch, C. Extracellular Vesicles as Delivery Vehicles of Specific Cellular Cargo. Cells 2020, 9, 1601. [CrossRef]

36. Simpson, R.J.; Jensen, S.S.; Lim, J.W.E. Proteomic profiling of exosomes: Current perspectives. Proteomics 2008, 8, 4083-4099. [CrossRef]

37. Fan, Z.; Zheng, W.; Li, H.; Wu, W.; Liu, X.; Sun, Z.; Hu, H.; Du, L.; Jia, Q.; Liu, Q. LOXL2 upregulates hypoxia-inducible factor-1 $\alpha$ signaling through Snail-FBP1 axis in hepatocellular carcinoma cells. Oncol. Rep. 2020, 43, 1641-1649. [CrossRef]

38. Ben-Yosef, Y.; Miller, A.; Shapiro, S.; Lahat, N. Hypoxia of endothelial cells leads to MMP-2-dependent survival and death. Am J. Physiol. Cell Physiol. 2005, 289, C1321-C1331. [CrossRef]

39. Yang, J.; Li, B.; He, Q.-Y. Significance of prohibitin domain family in tumorigenesis and its implication in cancer diagnosis and treatment. Cell Death Dis. 2018, 9, 580. [CrossRef]

40. Zhu, Y.; Tan, J.; Xie, H.; Wang, J.; Meng, X.; Wang, R. HIF- $1 \alpha$ regulates EMT via the Snail and $\beta$-catenin pathways in paraquat poisoning-induced early pulmonary fibrosis. J. Cell. Mol. Med. 2016, 20, 688-697. [CrossRef]

41. Bus, J.S.; Gibson, J.E. Paraquat: Model for oxidant-initiated toxicity. Environ. Health Perspect. 1984, 55, 37-46. [CrossRef]

42. McCarthy, S.; Somayajulu, M.; Sikorska, M.; Borowy-Borowski, H.; Pandey, S. Paraquat induces oxidative stress and neuronal cell death; neuroprotection by water-soluble Coenzyme Q10. Toxicol. Appl. Pharmacol. 2004, 201, 21-31. [CrossRef]

43. Vujić, T.; Schvartz, D.; Sanchez, J.-C. Quantitative Data-Independent Acquisition (DIA) analysis unraveled paraquat-induced cholesterol biosynthesis dysregulation in human brain microvascular endothelial cells. Unpublished, manuscript in preparation.

44. Rufino-Ramos, D.; Albuquerque, P.R.; Carmona, V.; Perfeito, R.; Nobre, R.J.; Pereira de Almeida, L. Extracellular vesicles: Novel promising delivery systems for therapy of brain diseases. J. Control Release 2017, 262, 247-258. [CrossRef]

45. Upadhya, R.; Zingg, W.; Shetty, S.; Shetty, A.K. Astrocyte-derived extracellular vesicles: Neuroreparative properties and role in the pathogenesis of neurodegenerative disorders. J. Control Release 2020, 323, 225-239. [CrossRef]

46. Leitolis, A.; Suss, P.H.; Roderjan, J.G.; Angulski, A.B.B.; da Costa, F.D.A.; Stimamiglio, M.A.; Correa, A. Human Heart ExplantDerived Extracellular Vesicles: Characterization and Effects on the In Vitro Recellularization of Decellularized Heart Valves. Int. J. Mol. Sci. 2019, 20, 1279. [CrossRef]

47. Vella, L.J.; Scicluna, B.J.; Cheng, L.; Bawden, E.G.; Masters, C.L.; Ang, C.-S.; Willamson, N.; McLean, C.; Barnham, K.J.; Hill, A.F. A rigorous method to enrich for exosomes from brain tissue. J. Extracell. Vesicles 2017, 6, 1348885. [CrossRef]

48. Rathinam, M.L.; Watts, L.T.; Narasimhan, M.; Riar, A.K.; Mahimainathan, L.; Henderson, G.I. Astrocyte mediated protection of fetal cerebral cortical neurons from rotenone and paraquat. Environ. Toxicol. Pharmacol. 2012, 33, 353-360. [CrossRef]

49. Bagley, A.C.; Krall, J.; Lynch, R.E. Superoxide mediates the toxicity of paraquat for Chinese hamster ovary cells. Proc. Natl. Acad. Sci. USA 1986, 83, 3189-3193. [CrossRef]

50. Yang, W.; Sun, A.Y. Paraquat-induced free radical reaction in mouse brain microsomes. Neurochem. Res. 1998, 23, 47-53. [CrossRef]

51. Wang, X.; Luo, F.; Zhao, H. Paraquat-Induced Reactive Oxygen Species Inhibit Neutrophil Apoptosis via a p38 MAPK/NF-kB-IL6/TNF- $\alpha$ Positive-Feedback Circuit. PLoS ONE 2014, 9, e93837. [CrossRef]

52. Yang, Y.; Boza-Serrano, A.; Dunning, C.J.R.; Clausen, B.H.; Lambertsen, K.L.; Deierborg, T. Inflammation leads to distinct populations of extracellular vesicles from microglia. J. Neuroinflamm. 2018, 15, 168. [CrossRef]

53. Chan, J.C.; Morgan, C.P.; Adrian Leu, N.; Shetty, A.; Cisse, Y.M.; Nugent, B.M.; Morrison, K.E.; Jašarević, E.; Huang, W.; Kanyuch, N.; et al. Reproductive tract extracellular vesicles are sufficient to transmit intergenerational stress and program neurodevelopment. Nat. Commun. 2020, 11, 1499. [CrossRef]

54. Yuana, Y.; Sturk, A.; Nieuwland, R. Extracellular vesicles in physiological and pathological conditions. Blood Rev. 2013, 27, 31-39. [CrossRef]

55. Xi, X.J.; Zeng, J.J.; Lu, Y.; Chen, S.H.; Jiang, Z.W.; He, P.J.; Mi, H. Extracellular vesicles enhance oxidative stress through P38/NF-kB pathway in ketamine-induced ulcerative cystitis. J. Cell Mol. Med. 2020, 24, 7609-7624. [CrossRef] [PubMed]

56. D’Acunzo, P.; Pérez-González, R.; Kim, Y.; Hargash, T.; Miller, C.; Alldred, M.J.; Erdjument-Bromage, H.; Penikalapati, S.C.; Pawlik, M.; Saito, M.; et al. Mitovesicles are a novel population of extracellular vesicles of mitochondrial origin altered in Down syndrome. Sci. Adv. 2021, 7, eabe5085. [CrossRef] [PubMed]

57. Van Dommelen, S.M.; van der Meel, R.; van Solinge, W.W.; Coimbra, M.; Vader, P.; Schiffelers, R.M. Cetuximab treatment alters the content of extracellular vesicles released from tumor cells. Nanomedicine 2016, 11, 881-890. [CrossRef] [PubMed]

58. Runz, S.; Keller, S.; Rupp, C.; Stoeck, A.; Issa, Y.; Koensgen, D.; Mustea, A.; Sehouli, J.; Kristiansen, G.; Altevogt, P. Malignant ascites-derived exosomes of ovarian carcinoma patients contain CD24 and EpCAM. Gynecol. Oncol. 2007, 107, 563-571. [CrossRef] [PubMed]

59. Im, H.; Shao, H.; Park, Y.I.; Peterson, V.M.; Castro, C.M.; Weissleder, R.; Lee, H. Label-free detection and molecular profiling of exosomes with a nano-plasmonic sensor. Nat. Biotechnol. 2014, 32, 490-495. [CrossRef]

60. Kucharzewska, P.; Christianson, H.C.; Welch, J.E.; Svensson, K.J.; Fredlund, E.; Ringnér, M.; Mörgelin, M.; Bourseau-Guilmain, E.; Bengzon, J.; Belting, M. Exosomes reflect the hypoxic status of glioma cells and mediate hypoxia-dependent activation of vascular cells during tumor development. Proc. Natl. Acad. Sci. USA 2013, 110, 7312-7317. [CrossRef] 
61. Puhm, F.; Afonyushkin, T.; Resch, U.; Obermayer, G.; Rohde, M.; Penz, T.; Schuster, M.; Wagner, G.; Rendeiro, A.F.; Melki, I.; et al. Mitochondria Are a Subset of Extracellular Vesicles Released by Activated Monocytes and Induce Type I IFN and TNF Responses in Endothelial Cells. Circ. Res. 2019, 125, 43-52. [CrossRef]

62. Jang, S.C.; Crescitelli, R.; Cvjetkovic, A.; Belgrano, V.; Olofsson Bagge, R.; Sundfeldt, K.; Ochiya, T.; Kalluri, R.; Lötvall, J. Mitochondrial protein enriched extracellular vesicles discovered in human melanoma tissues can be detected in patient plasma. J. Extracell. Vesicles 2019, 8, 1635420. [CrossRef]

63. Xie, H.; Tan, J.-t.; Wang, R.-1.; Meng, X.-X.; Tang, X.; Gao, S. Expression and significance of HIF-1 $\alpha$ in pulmonary fibrosis induced by paraquat. Exp. Biol. Med. 2013, 238, 1062-1068. [CrossRef]

64. Alural, B.; Ozerdem, A.; Allmer, J.; Genc, K.; Genc, S. Lithium protects against paraquat neurotoxicity by NRF2 activation and miR-34a inhibition in SH-SY5Y cells. Front. Cell. Neurosci. 2015, 9. [CrossRef]

65. Wang, X.; Zhou, Y.; Gao, Q.; Ping, D.; Wang, Y.; Wu, W.; Lin, X.; Fang, Y.; Zhang, J.; Shao, A. The Role of Exosomal microRNAs and Oxidative Stress in Neurodegenerative Diseases. Oxid. Med. Cell. Longev. 2020, 2020, 3232869. [CrossRef]

66. Dozio, V.; Sanchez, J.C. Profiling the proteomic inflammatory state of human astrocytes using DIA mass spectrometry. J. Neuroinflamm. 2018, 15, 331. [CrossRef] 